\title{
Implementation of Early Childhood Education: A Case Study in Nigeria
}

\author{
Osho Lauretta Oluwafemi ${ }^{1, *}$, Aliyu $\mathrm{Nma}^{2}$, Okolie Osita $^{3}$, Onifade Olugbenga ${ }^{3}$ \\ ${ }^{1}$ Department of Computer Science, Federal University of Technology, Minna, Nigeria \\ ${ }^{2}$ School of Education, Niger State College of Education, Minna, Nigeria \\ ${ }^{3}$ Department of General Studies, Federal University, Dutse, Nigeria \\ *Corresponding Author: laurattachristi@gmail.com
}

Copyright (C) 2014 Horizon Research Publishing All rights reserved.

\begin{abstract}
Early Childhood Education (ECE) is the education given in educational institutions to children prior to entering the primary schools. Recently, there have been heightening concerns raised by stakeholders concerning the quality of education in Early Childhood Development and Education (ECDE). This paper assesses the level of implementation of ECE in Chanchaga local government area, a local government in one of the north-central states in Nigeria. The sample size was 32 teachers, selected from 10 schools (out of 31 in the local government area). Questionnaire, interviews, and observations were used as research instruments. The study found out that while the enrolment level is high and, appreciably, there are teachers who specialize in ECE, basic teaching/learning and other basic resources are sparsely available, and most of the ECE centers are overpopulated. Employment of more ECE specialist teachers, training/retraining of caregivers/teachers, and provision of necessary resources would go a long way to actualize effective implementation in the local government.
\end{abstract}

Keywords Early Childhood Education, ECE, Education, Implementation, Chanchaga, Niger State, Nigeria, Teaching/Learning

\section{Introduction}

\subsection{Background of Study}

The definition of Early Childhood Education (also known as Early Childhood learning and Early Education) varies in scope and seem to be closely linked to geographical locations. While the main thrust of some definitions is based on age bracket, some consider the environment within which the education is delivered, others combine both. ECE has been considered to be a pre-school, semi-formal education outside the home [1]. It includes the crèche, the nursery and kindergarten [2]. This program was introduced for children between the ages of $0-5$ years. In Nigeria, ECE came into being in order to assist and bring early child

care within the reach of majority of Nigerian children, particularly those in rural and low socio economic areas. Hence, the Nigerian Educational research and Development Council in collaboration with UNICEF is implementing a low cost, community based and non-formal day care program. Locally sourced educational materials are introduced to caregivers, to provide avenues for cognitive, affective and psychomotor development of the child [3].

Nigeria subscribed to the Convention Rights of the Child (CRC). In order to domesticate it, a National Policy for Integrated Early Childhood Development (IECD) was developed and adopted in 2007. It was geared at accommodating children between the ages of 0 to 5 . This was consequent upon the discovery that the growth, survival, and development of children within this age group are mutually dependent. The policy would incorporate and develop further interventions on the Nigerian child from relevant sectors. It is based on the premise that ECE for these children, which caters for their physical, mental and social development, is heavily dependent on families and caregivers support [4].

\subsection{Statement of Problem}

Since the commencement of the implementation of the National Policy on Education in Nigeria which seeks to ensure an optimal and qualitative ECE, stream of concerns have been raised by stakeholders in respect of the quality of education in Early Childhood Development and Education (ECDE) and its actual implementation. Despite all measures put in place by the Federal Ministry of Education in Nigeria, there are still some lapses in the implementation and non-implementation of this program.

There is no doubt that the implementation of Early Childhood Education requires the collaborative effort/input of all stakeholders, including the government, parents/guardians, and school authorities. While the government is expected to provide necessary teaching and learning resources, the availability of relevant age-grade 
pupils, and the cooperation of parents/guardians in enrolling their children/wards cannot be overemphasized. But is Early Childhood Education actually implemented in Chanchaga Local government? If yes, what are the factors that have aided its implementation? But if no, what are responsible?

\subsection{Objectives of Study}

This project seeks to assess the level of implementation of ECE in Chanchaga local government area of Niger state, Nigeria. Chanchaga local government covers the most part of Minna, which is the capital of Niger state. From observation, the local government can be said to be the most developed local government of Niger state.

This study was borne out of a curiosity to know the state of factors that are necessary for the implementation of Early Childhood Education particularly in public primary schools in Nigeria.

This study would go a long way to highlight the major problems, if any, facing the implementation of Early Childhood Education program particularly in Chanchaga Local Government of Niger State, and in proffering solutions that could be adopted to tackle the challenges they are facing. It will also help to make such schools very effective, achieve good results in impacting knowledge and better preparation for primary education.

\section{Early Childhood or Pre-primary Education in Nigeria}

According to [1], ECE in Nigeria started with the British colonial masters. It soon spread to their employee Nigerians who tried to imitate their masters. At that time only the wealthy could afford to send their children for such education. However, the Universal Primary Education (UPE), an initiative that afforded free education proved to be the lifeline for the children from poor homes. As more children were sent to school the availability of these children for household servants declined rapidly. The needs of working mothers at that time for where to keep their babies thus became the catalyst for the growth of nursery schools in Nigeria.

Akinbote [5] differed in the origin of pre-school in Nigeria. Church premises served as the venues for the schools, organized by missionaries, with their wives often in charge of their children and those of their members. A section of Sunday schools was also dedicated for focusing on these children. As the number of the children increased, school days were soon spread from Sunday alone to span Monday to Friday.

An investigation conducted in 2003 revealed that more than two-fifth (42\%) of the sampled ECC facilities in Nigeria was private-owned. Government-owned accounted for $34 \%$, and $21 \%$ by local communities [6]. As time went on, it became necessary for the government to increase its involvement in pre-school education in the country. By 2004, this segment of education had been integrated into the Universal Basic Education programme by the UBE Act (2004). All children within the pre-school age bracket were entitled to be admitted without paying school fees into any ECE center, which was planned to be integrated into every public primary school [7]. For the year 2003/2004, the gross and net enrolment ratios were $14.7 \%$ and $10.9 \%$ respectively. The normative age groups under consideration were $3-5$ years of age [6].

Considering the volatility of ECE, knowing that the products of the educational system of the country is largely tied to the effectiveness of pre-school education, the need for more coordination cannot be overemphasized. The Nigerian National Policy of Education (2004) document defined the roles of all stakeholders to ensure hitch-free implementation of ECE [8].

Olaleye et al [9] explored the quality of ECE in Ekiti state of Nigeria. Their findings revealed low rating of the qualities of academic staff and parental participation. The quality of learning activities was found to be in tandem with the National Policy on Education.

\section{Research Methodology}

\subsection{Research Design}

In order to achieve the main objective of this project, which is to highlight factors affecting the implementation of Early Childhood Education (ECE) in Chanchaga local government of Niger state, it was natural to obtain first hand information on the state of ECE in the local government by applying a survey research design methodology. To actualize this, schools were visited, with the teachers consulted as the primary source of information. Observation of the author and input from other stakeholders are used as the secondary source. Collated data are analyzed descriptively and inferentially using the necessary statistical tools.

\subsection{Population of the Study}

There are 31 primary schools in Chanchaga Local government of Niger state. Each of these primary schools runs a nursery school section, specifically nurseries one and two.

\subsection{Sample of the Study}

10 out of the schools were selected. Stratified random sampling method was employed in the selection, with the local government divided into 6 groups, and schools randomly chosen from each group. In each school a questionnaire was administered for each class offering ECE. A total of 32 questionnaires were issued based on the number of nursery classrooms in each school. Out of the thirty two 
questionnaires issued, on collation, two were rejected due to improper filling, mistakes that may be due to lack of understanding of one or more crucial questions, or non-adherence to the instructions contained in the questionnaire. The remaining valid thirty questionnaires are used for the necessary analyses.

\subsection{Research Instrument}

To obtain basic information on the list of schools, location of each school, and the implementation or otherwise of ECE, the Head of Department for schools in the office of the Education Secretary for Chanchaga Local government area was interviewed. However, the primary research instrument used was questionnaire, which was administered to teachers/caregivers in the ECE centres or primary schools that are running Nursery sections. Also, the head-teachers of some of the visited schools granted the researchers audience as they were interviewed. Out of the 10 schools visited, only 3 head-teachers actually cooperated. We also made observation of the learning environment and other available resources/facilities on ground and the amount of work the teachers were doing.

\subsection{Data Collection Procedure}

Data were collected from the responses to interview of the Head of Department for Schools, in the office of the Education Secretary of Chanchaga local government, school head teachers and classroom teachers. Information gathered include list of all the primary schools in Chanchaga local government. Permission to visit as many of the schools as necessary was also obtained.

Teachers in the ten visited schools were personally handed the questionnaires, which were collected immediately upon their filling the required details. In some schools, the filled questionnaires were collected at a later date. It must be reported that some, out of fear, did not personally fill the questionnaires. Instead, they were interviewed and we used their responses to fill on their behalf.

Data was also collected from responses, to interviews, of the head teachers to ascertain the validity of what the teachers filled in their questionnaires. We were also allowed to move around the classrooms and school environment to see things for ourselves and determine how good the teaching and learning process and environment were.

\subsection{Scoring of Data Collected}

A total of thirty two questionnaires were administered in the ten schools. In the process of collation, two of the filled questionnaires were invalid, while the remaining thirty met the conditions for stratification.

The questions contained in the questionnaires are basically those requiring "Yes" or "No" answers. A table was drawn to enter all the information given in all the questionnaires. If the answer given for a particular question was "Yes," 1 is written in the table against that particular question and if the answer was "No," 0 is written in the table against that question for that particular respondent. For questions that involved ticking of choices, a selected choice is taken as selecting a "Yes" option, while those choices not ticked were taken as selecting a "No."

\subsection{Data Analysis Procedure}

For the purpose of data analysis, we employ some statistical tools and techniques for both descriptive and inferential presentation of the results. Charts and other descriptive tools were used to give clear and pictorial representation of collated data. Hypotheses were developed and tested using statistical techniques, and necessary deductions made.

\section{Results and Discussion of Findings}

\subsection{General Questions}

The results of the data collated from the general questions in the questionnaire, are presented in the table 1 and figure 1 below.

Table 1. Results of General Questions

\begin{tabular}{ccc}
\cline { 2 - 3 } & $\begin{array}{c}\text { Yes } \\
\text { N (\%) }\end{array}$ & $\begin{array}{c}\text { No } \\
\text { N (\%) }\end{array}$ \\
\hline Have you any knowledge of ECE? & $29(96.7 \%)$ & $1(3.3 \%)$ \\
Do you understand what ECE is? & $29(96.7 \%)$ & $1(333 \%)$ \\
$\begin{array}{c}\text { Does your school have facilities for } \\
\text { ECE? }\end{array}$ & $28(93.3 \%)$ & $2(6.7 \%)$ \\
$\begin{array}{c}\text { Do you have pupils enrolled for ECE? } \\
\begin{array}{c}\text { Any understanding and appreciation } \\
\text { from parent/guardians? }\end{array}\end{array}$ & $29(96.7 \%)$ & $1(3.3 \%)$ \\
\hline
\end{tabular}

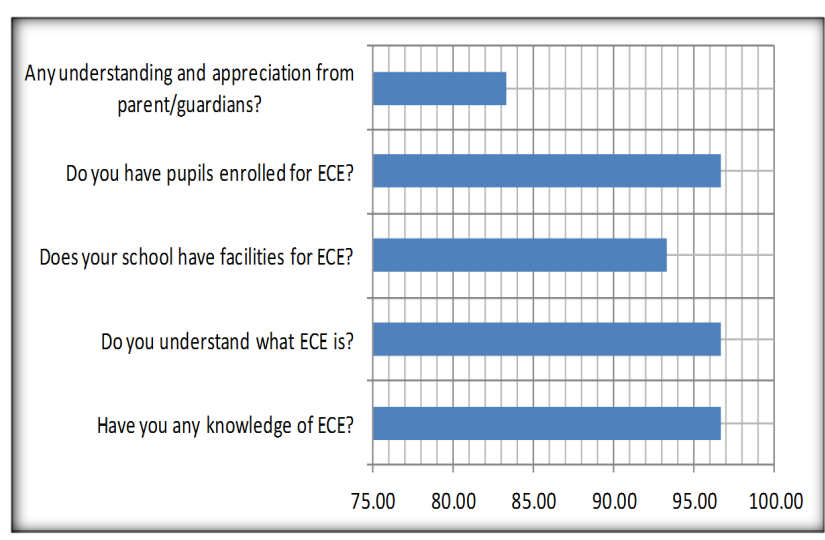

Figure 1. Bar chart representing results of general questions

\subsection{Teaching and Learning Resources}

For the availability or otherwise of facilities and resources available for ECE in Chanchaga Local Government we have 
the table of information in table 2. These are also displayed pictorially in figure 2 .

Table 2. Teaching and Learning Resources

\begin{tabular}{ccc} 
& Yes & No \\
\cline { 2 - 3 } & $\mathbf{N}(\mathbf{\%})$ & $\mathbf{N}(\mathbf{\%})$ \\
\hline Teachers specialized in ECE & $20(66.7 \%)$ & $10(33.3 \%)$ \\
Well ventilated classrooms & $27(90.0 \%)$ & $3(10.0 \%)$ \\
Child sized furniture & $19(63.3 \%)$ & $11(36.7 \%)$ \\
Spacious playground & $20(66.7 \%)$ & $10(33.3 \%)$ \\
Beds/beddings & $0(0.0 \%)$ & $30(100.0 \%)$ \\
TV/computer & $2(6.7 \%)$ & $28(93.3 \%)$ \\
Bathrooms & $1(3.3 \%)$ & $29(96.7 \%)$ \\
Nature table/ corner & $7(23.3 \%)$ & $23(76.7 \%)$ \\
Toys and models & $1(3.3 \%)$ & $29(96.7 \% 0$ \\
Charts and wall drawings & $14(46.7 \%)$ & $16(53.3 \%)$ \\
Playing equipments, e.g see-saw, & $3(10.0 \%)$ & $27(90.0 \%)$ \\
swings etc & $9(30.0 \%)$ & $21(70.0 \%)$ \\
Safe and clean water & $11(36.7 \%)$ & $19(63.3 \%)$ \\
Toilet(s) &
\end{tabular}

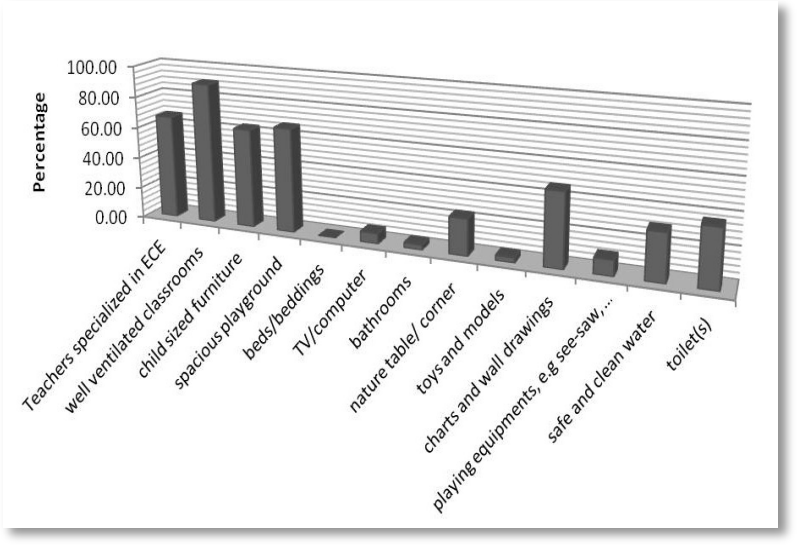

Figure 2. A Bar Chart showing teaching and learning resources available for $\mathrm{ECE}$

\subsection{Communication Medium}

The communication medium for children within ECE age grade, who have only had interactions with their immediate environment, is very important. For ECE in Chanchaga Local Government Area we have the data in table 3. Figure 3 is the representation in pie chart.

Table 3. A Table showing the languages of communication

\begin{tabular}{cc}
\cline { 2 - 2 } & Population \\
& $\mathrm{N}(\%)$ \\
\hline English only & $2(7.1 \%)$ \\
Hausa only & $0(0.0 \%)$ \\
English and Hausa only & $24(85.7 \%)$ \\
Other languages only & $0(0.0 \%)$ \\
English and other languages & $2(7.1 \%)$ \\
Total & $28(100.0 \%)$ \\
\hline
\end{tabular}

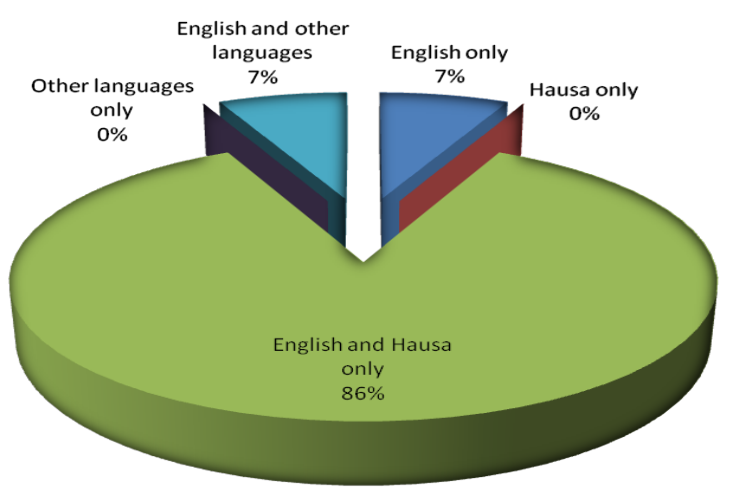

Figure 3. A Pie Chart showing Communication Languages

\subsection{Teacher-Child Ratio}

For teacher-child ratio, that is, the average number of pupils under each teacher, we have the following responses, as tabulated in table 4 , and displayed in figure 4 .

Table 4. A Table showing Teacher-Child Ratio

\begin{tabular}{cc}
\cline { 2 - 2 } & $\begin{array}{c}\text { Population } \\
\mathbf{N}(\mathbf{\%})\end{array}$ \\
\hline $1: 10$ & $0(0.0 \%)$ \\
$1: 15$ & $2(7.4 \%)$ \\
$1: 20$ & $1(3.7 \%)$ \\
$1: 25$ & $4(14.8 \%)$ \\
$1: 30$ & $4(14.8 \%)$ \\
$1:$ above 30 & $16(59.3 \%)$ \\
Total & $\mathbf{2 7 ( 1 0 0 . 0 0 \% )}$ \\
\hline
\end{tabular}

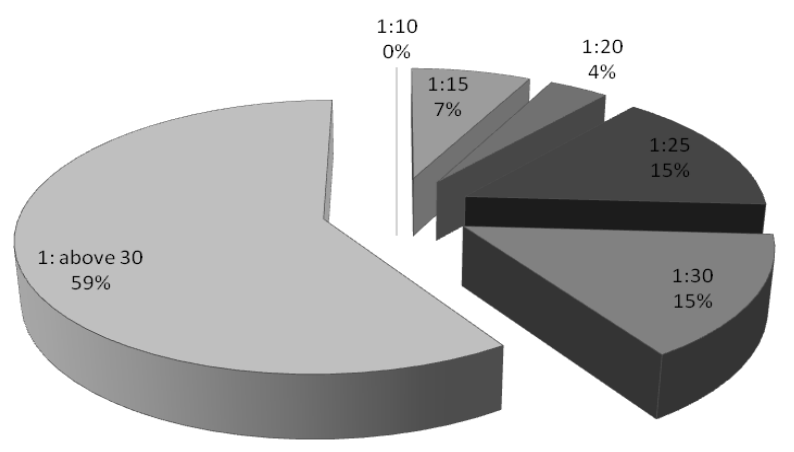

Figure 4. A Pie Chart showing Teacher-Child Ratio

\subsection{Learning Groups}

Learning groups here refer to the age groups and the classes that the children are categorized or grouped, and are taught in. In Chanchaga local government, the available learning groups for all the ECE centres are represented by table 5 and figure 5 . 
Table 5. A representation of learning groups

\begin{tabular}{ll}
\cline { 2 - 2 } & $\begin{array}{l}\text { Population } \\
\mathbf{N}(\mathbf{\%})\end{array}$ \\
\hline Creche/Daycare(0 - 2 years) & $0(0.0 \%)$ \\
Pre-Nursery $(2-3$ years $)$ & $0(0.0 \%)$ \\
Nursery $(3-5$ years $)$ & $28(100.0 \%)$ \\
Total & $\mathbf{2 8}(\mathbf{1 0 0 . 0 \% )}$ \\
\hline
\end{tabular}

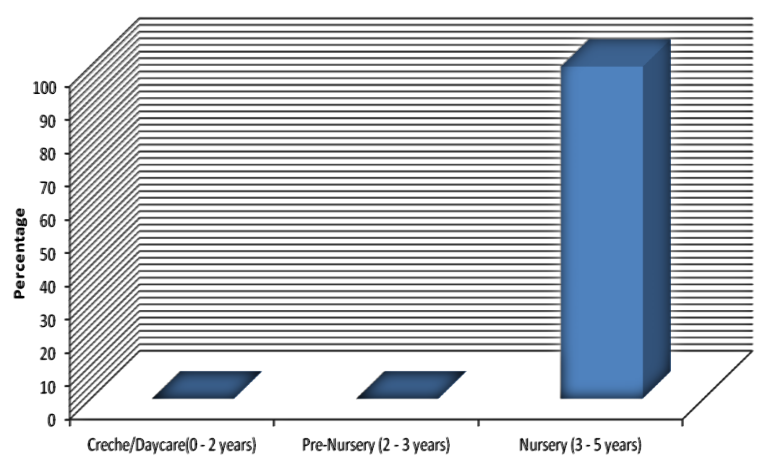

Figure 5. Bar chart showing learning groups

\subsection{Test of Hypothesis}

Based on the problem statement and research questions vis-à-vis all collated responses, we develop and test our hypotheses to highlight the effects of factors affecting the implementation of ECE in Chanchaga local government.

\subsubsection{Parents'/Guardians' Understanding and Appreciation of the Need for ECE}

Considering the responses, is it sufficient to conclude that understanding and appreciation of ECE by parents/guardians increases the enrollment of pupils for ECE, using $10 \%$ significant level?

Using t-test, assuming that the population of paired difference is approximately normally distributed, we are interested in testing following hypotheses:

$\mathrm{H}_{0}$ : The level of appreciation of ECE by parents/guardians does not increase the enrollment of pupils for ECE.

$\mathrm{H}_{1}$ : The level of appreciation of ECE by parents/guardians increases the enrollment of pupils for ECE.

Computing the value of the test statistics, we have that $t=-1.6820$. From this value, we know that the alternative hypothesis is one-sided (left-tailed). Hence, using the significance level $\alpha=0.1$, and degree of freedom, $d f=30-1=29$, from the $t$-Distribution table, the critical value $=-1.311$.

Since the computed $t$ value is greater than the tabulated value, we reject the null hypothesis. We conclude that understanding and appreciation of ECE by parents/guardians has a positive effect on pupils' enrollment for ECE.

\subsubsection{Availability or Otherwise of Necessary Teaching and Learning Resources}

The implementation of ECE evidently depends on the equitable distribution of teaching and learning resources in all ECE centres of the local government.

Testing at significance level, $\alpha=0.05(5 \%)$, can we confidently say that teaching and learning resources in Chanchaga Local Government are evenly distributed?

From the null and alternative hypotheses:

$\mathrm{H}_{0}$ : Teaching and learning resources for ECE in Chanchaga local government are evenly distributed.

$\mathrm{H}_{1}$ : Teaching and learning resources for ECE in Chanchaga local government are not evenly distributed.

We have the computed value as 94.1791. Using the chi-square test, for $\alpha=0.05$, and degree of freedom, $d f=13-1=12$, from the chi-square distribution table, the critical value of $\chi^{2}=21.02$. Since $94.1791>21.026$, we reject the null hypothesis, and thus conclude that teaching and learning resources are not evenly distributed in ECE centres in Chanchaga local government.

\subsection{Discussion of Findings}

\subsubsection{General Overview}

Considering the responses from table 1 and figure 1, it could be seen that only a few of the teachers for ECE do not have knowledge of what ECE is actually about. Considering the simple fact that these teachers are supposedly those who specialize in ECE, it is much unexpected to discover some of the teachers, $3.33 \%$ in this case, not having understanding of their roles as caregivers/teachers of delicate children, since they have need for special care and attention. The need for more education and retraining of teachers for proper understanding and more skills in the handling of little children of such an age cannot be overemphasized.

More than $90 \%$ of the respondents revealed they had facilities for the running of ECE. However, from responses, these teaching and learning resources are very limited in supply.

In respect of pupils' enrollment, one can infer that enrollment of pupils is not a barrier to the implementation of ECE in Chanchaga local government. However, efforts should be made to get the remaining $3.33 \%$ to school.

Perceived understanding and appreciation of parents/guardians towards ECE by teachers can also be seen to be on the high side $(83.3 \%)$. The positive effect of this is evident on the percentage level of enrollment. This was corroborated by the test of the null and alternative hypotheses, which confirmed that the enrollment of pupils for ECE is encouraged by the understanding and appreciation of parents/guardians.

\subsubsection{Availability of Resources}

Considering table 2 and figure 2, first, it is very surprising to find out from the confession of some respondents that up to one-third of the primary schools in Chanchaga local governments do not have teachers who specialize in ECE. This is against the backdrop that all the schools offer ECE. 
This simply spells the fact that an appreciable percentage of the pupils are not being given the best.

From our observation, only $30 \%$ of the schools had furniture suitable for ECE, and in these schools the classes were overpopulated. $10 \%$ of the schools had no furniture for both teachers and pupils, while in some $10 \%$ only the teachers had furniture to use. For the remaining schools, the available furniture could not accommodate the pupils. This is obviously a very bad situation that should be looked into and given urgent attention by relevant educational body.

It is also evident that other equally essential teaching and learning materials indispensible for effective teaching and learning in the ECE level of education are unavailable in most schools. Resources including television/computer systems, nature table/corners, toys and models, charts and well drawings and even playing equipments like see-saw, merry- go - round, slides etc. are almost completely not available in any of the schools.

We also found out that some very necessary facilities for the convenience of the children like toilets, bathrooms, beds/beddings and clean and safe water are not available. It is a known fact that children of ages 0 to 5 years have little or no control over their need for using the toilet. It is also known that they sleep easily due to their low concentration span, and always need to drink water and be cleaned very often. One can only wonder how these needs would be met in the absence of the required basic facilities. Olaleye et al [8] revealed similar scenario for Ekiti state.

\subsubsection{Languages of Communication}

The data represented on table 3 and figure 3 shows that the caregivers/teachers communicate with the children mostly in English and Hausa, which is the language that most of the children understand, as it is the language of their local community. This no doubt will go a long way to foster proper and adequate communication between teachers and pupils, and further promote learning. This is a commendable development as the child feels more comfortable to express himself in a language he/she understands and can identify with.

\subsubsection{Teacher - Child Ratio}

Considering table 4 and figure 4 , the data has shown that most of the ECE learning centres in Chanchaga Local Government Area have overpopulated classrooms. Specifically, most of the centres have more than thirty pupils per teacher. This does not promote effective learning as children in ECE centres need very special and close attention and communication. They need a careful one-to-one relationship with their teachers and as such, a teacher cannot adequately handle more than thirty pupils. This way, there is no effective teaching and learning.

\subsubsection{Available Learning Groups}

Table 5 and figure 5 show that there is really no crèche/Daycare or Pre-Nursery levels of education which is meant for children between the ages of 0 to 3 years of age.
This may be attributed partly to the fact that mothers of most of the children of this age grade are working class women, who need to be close to their children. They would prefer to have ECE centres close to their places of work, with facilities for pre-nursery level of education. To this effect, the need for government to establish these ECE centres with such provisions especially for working mothers who work in places where children are not allowed is essential. This will have a very strong effect on the work done by such mothers and will go a very long way in improving the job efficiency of the workforce in Chanchaga Local Government Area.

\section{Conclusion}

This project sought to highlight factors affecting the implementation of ECE in Chanchaga local government. The level of availability of resources was assessed. While there are classrooms and spacious playgrounds, other basic resources like beds/beddings, TV/computers, bathrooms, toys and models, and playing equipments, to mention but few, are in very short supply. Most of the classes were also found to be overpopulated.

Worthy of commendation is the understanding and appreciation of parents/guardians of the need for ECE, and the use of most children's first language for teaching. As a matter of fact, the interviews revealed some information that could not have been gathered from collation of the findings from the questionnaires. Also, we discovered that some of the responses collated from the questionnaires conflicted with the results of our observations. In the long run, we concluded that it was better to combine the results from the interviews, questionnaires and our personal findings from observations. However, the collated data were used majorly for analysis and consequent inference.

To ensure an effective implementation of ECE in Chanchaga local government, the following are hereby recommended:

- Training and retraining of caregivers/teachers should be made a vital part of the education process.

- Teaching and learning materials like furniture for both teachers and pupils, television sets/computer systems, nature table/corners, toys and models, charts and well drawings and playing equipments like see-saw, merry- go - round, slides etc. should be made a vital provision in all learning centres for effective teaching and learning.

- Toilets, bathrooms, beds/beddings, clean and safe water and other basic facilities/resources should be made available.

- A maximum of 30 pupils should be allocated to a teacher for effective teaching and learning. This may require employing more teachers who specialize in ECE.

- Creche/Daycare levels should be introduced in all ECE learning centres to help working mothers.

It is strongly believed that if the above recommendations 
are implemented in Chanchaga Local Government Area, the challenges confronting Early Childhood Education in the local government will be a thing of the past.

\section{Acknowledgements}

We sincerely appreciate the Teacher's Registration Council of Nigeria (TRCN), for providing the platform for us, who would not have had the opportunity, to be registered teachers. We also appreciate Dr. Rotimi Williams, the State Officer, National Examination Council (NECO), Kano, for providing one material whose benefit will ever go beyond providing relevant information used in this paper.

\section{REFERENCES}

[1] Oyewumi, A., Alhassan, A. B., and Ofoha, D. (2010). Management of Early Childhood Education (ECE 412), National Open University (NOUN). Available at: http://www.nou.edu.ng/noun/NOUN_OCL/pdf/EDUs/ ECE\%20412.pdf

[2] National Policy on Education (2004).

[3] Zakariyah, I. (2012). Lecture note on Curriculum and Resources. Centre for Continuing Education, College of
Education, Minna.

[4] Guidelines for implementing National Policy in integrated early childhood development in Nigeria, Federal Ministry of Education, 2011.

[5] Akinbote, O. (2006). Origin and development of Early Childhood Education. National Open University (NOUN). Available at: http://www.nou.edu.ng/ noun/NOUN_OCL /pdf/EDUs/

ECE\%20112\%20ORIGIN\%20\&\%20DEVPT\%20OF\%20EC E.pdf

[6] Education for All Global Monitoring Report 2007. Nigeria, Early Childhood Care and Education (ECCE) programs. Compiled by UNESCO International Bureau of Education (IBE), Geneva, Switzerland (2006). Available on: http://unesdoc.unesco.org/images/ 0014/001472/147201e.pdf

[7] Teachers for the Future: Meeting Teachers Shortages to Achieve Education for All. National Policy Brief, Nigeria. Available on: http://www.ilo.org/wcmsp5/groups/public/---ed_dialog ue/---sector/documents/publication/wcms_161963.pdf

[8] Nakpodia, E. D. (2011). Early Childhood Education: Its policy formulation and Implementation in Nigerian Educational System. African Journal of Political Science and International Relations, Vol. 5(3), pp. 159-163. March 2011.

[9] Olaleye, O., Florence, O., and Omotayo, K.A. (2009). Assessment of Quality in Early Childhood Education in Ekiti State, Nigeria. World Applied Sciences Journal 7 (5): 683-688, 2009, ISSN 1818-4952. 